\title{
ALGUNAS IDEAS EN TORNO AL ESTUDIO DE LOS ABOGADOS EN CHILE
}

\author{
Iñigo de la Maza Gazmuri*
}

Lo que podemos advertir especialmente en los grupos profesionales es una fuerza moral capaz de doblegar el egoismo individual, nutriendo a sus miembros con un sentimiento más vigoroso de solidaridad común y previniendo que la ley del más fuerte se aplique brutalmente en las relaciones industriales y comerciales.

Emile Durkbeim

Creo que debiésemos clasificar a los abogados dentro de historia natural de los monstruos.

Jobn Keats

RESUMEN: Pese a su evidente importancia bistórica, los abogados no han sido, hasta la fecha, suficientemente estudiados en Chile. Las páginas siguientes intentan esbozar algunas directrices de estudio que deberían resultar útiles para evaluar las fuertes tensiones que ba venido experimentando la profesión legal a partir de la segunda mitad del siglo XX. Con este objetivo se utilizan algunos enfoques propios de la sociología de las profesiones para intentar explicar a grandes trazos la evolución de la profesión legal en Chile. Concluido esto, la parte final de este trabajo busca aplicar estos enfoques a la situación actual de los abogados en Chile.

Palabras clave: Abogados - Profesión legal - Enfoques sociológicos Regulación.

ABSTRACT: Despite its evident bistoric importance, the lawyers have not been, up to date, sufficiently studied in Chile. The following pages intend to outline some research guidelines that should be of use to evaluate the strong tensions that the legal profession has been experiencing since the second half of the 20th century. Some approaches pertaining to the sociology of professions are used

Profesor investigador, Fundación Fernando Fueyo Laneri. Facultad de Derecho Universidad Diego Portales. Master in the Science of Law, Stanford University. Profesor de Derecho Civil de la Facultad de Derecho de la Universidad Diego Portales. Director del Programa de Derecho y Tecnologías de la Información de la Fundación Fernando Fueyo Laneri. Arrículo recibido el 2 de marzo de 2005. Aceptado por el Comité Editorial el 16 de mayo de 2005 . 
with the objective to try to explain, in a broad sense, the evolution of the practice of the law in Chile. Once concluded, the final part of this paper seeks to apply these approaches to the present situation of the lawyers in Chile.

Key words: lawyers - legal profession - sociologic approaches regulation,

SUMARIO: 1. El enfoque funcionalista. 2. La tradición weberiana. 3. El caso chileno. 4. La tradición marxista. 5. La estratificación. 6. Un enfoque complementario. 7. Especulando acerca del caso chileno. Los abogados y el Estado. 8. In medio veritas est.

Durante el siglo XIX y la primera mitad del XX los abogados en Chile gozaron de un prestigio social -tanto en el foro como en la política- que actualmente resulta difícil de imaginar. Durante la segunda mitad del siglo XX, las cosas cambiaron. En política se percibió a los abogados como una profesión que obstaculizaba el progreso. En conjunto con lo anterior, desde hace ya algunos años se han comenzado a escuchar persistentes murmullos respecto de las falencias éticas de la profesión legal $y$, al interior de esta, quejas sobre las dificultades para encontrar trabajo y una baja en las remuneraciones. Esta descripción resulta, por cierto, algo gruesa. Me interesa mantenerla, sin embargo, para plasmarla en dos imágenes de los abogados, una derivada del enfoque funcionalista de las profesiones y, la otra, más cercana a la tradición weberiana. Concluido esto, indico, cómo se acomodan ambas imágenes a la historia de los abogados en Chile y doy algunas noticias sobre qué puede enseñarnos aún la tradición marxista respecto a los abogados. Finalmente, describo en sus líneas más gruesas, un enfoque alternativo e intento aplicarlo a los abogados en el Chile de hoy.

\section{EL ENFOQUE FUNCIONALISTA}

La idea que subyace a autores como DURKHEIM y PARSONS -probablemente los representantes más conspicuos de este enfoque- es que las profesiones constituyen cuerpos intermedios, interfaces que permiten una relación fluida entre el poder y los ciudadanos comunes y corrientes, que permiten el reemplazo de la solidaridad social orgánica -basada en las coincidencias entre los sujetos- por la solidaridad mecánica, manteniendo el orden social a través de la provisión de patrones de comportamiento socialmente valiosos. Así, por ejemplo, PARSONS señala que: "El profesional no se concibe como alguien que persigue sus intereses personales, sino como alguien que presta servicios a sus pacientes o clientes, o a 
valores impersonales como el avance de la ciencia"1. Junto al altruismo que reconoce este enfoque a la actividad de los profesionales, una segunda característica define la fisonomía de las profesiones: su competencia técnica superior que les permite llenar algún tipo de necesidad social determinada. Para cumplir con su función social, las profesiones requieren, básicamente dos cosas: (1) que el Estado les conceda autonomía en el control de su actividad y (2) que les garantice un cierto monopolio sobre las actividades que desarrollan. Ambas cosas resultan consistentes con las características de las profesiones. De una parte, el cuerpo de conocimiento que manejan las profesiones inhabilita a quienes no han sido "iniciados" en él para juzgar el desempeño de sus miembros, esta tarea es llevada a cabo por sus propias asociaciones y códigos de ética. Por otra, para realizar sus funciones adecuadamente, las profesiones requieren que el Estado les garantice un umbral de remuneraciones, esto justifica el monopolio.

\section{LA TRADICIÓN WEBERIANA}

Si para los funcionalistas el problema que origina la actividad profesional es el orden social, para la tradición weberiana el origen de estas es la competencia por recompensas sociales y económicas. Las profesiones entonces constituyen grupos que intenten asegurar ambas conquistando un mercado determinado. En palabras de ABEL:

Para Max Weber y otros en su tradición teórica (...) el análisis comienza con la esfera de distribución. La cuestión central es cómo los actores económicos buscan y consiguen ventajas competitivas dentro de un mercado relativamente libre -uno construido por el Estado, pero dominado por agentes privados. Las metas son las recompensas económicas y la posición social, las cuales son resultado en parte de la riqueza y en parte de la legitimación ${ }^{2}$.

Para conseguir ambas metas las profesiones deben lograr que sus servicios se conviertan en una mercancía y, una vez conseguido esto, cerrar el mercado en el que se transa esa mercancía a otros posibles competidores. Así las cosas, en la explicación weberiana de las profesiones, el énfasis se desplaza desde la función que cumplen las profesiones a los grupos que las constituyen. En segundo lugar, la organización de esos grupos se orienta hacia la obtención de un mercado cerrado donde ofrecer su

Parsons, Thlcotr: Essays in Sociological Theory, Revised Edition, Second Printing, Illinois, 1958 , p. 35.

2 American Lawyers, Oxford University Press, Nueva York, 1989, p. 15. 
mercancía. En tercer lugar la monopolización del mercado donde se ofrece la mercancía opera bajo una cobertura ideológica doble: el altruismo de quienes ejercen la profesión y la complejidad técnica de sus conocimientos, esto permite demandar, por una parte, la exclusividad en el comercio de la mercancía y, por otra, que el control de la actividad profesional se desplace desde el Estado hacia la profesión.

\section{El CASO CHILENO}

Hasta mediados del siglo XX los abogados poseyeron en Chile una imagen cercana a la propuesta por el enfoque funcionalista. El abogado aparecía como el titular de un saber algo arcano y un sujeto altruista - dispuesto a servir a los más pobres a través de su práctica profesional y de la institución del curno o su participación en política- regulado por un código de ética, cuyas reglas eran aplicadas por el Colegio de Abogados, al cual los profesionales debían afiliarse obligatoriamente. Mi impresión es que esta imagen de los abogados era, en parte importante, el resultado de algunos factores estructurales, entre ellos un número bajo de abogados (hasta 1981 había en Chile únicamente cinco facultades de derecho), la falta de competencia por parte de otras profesiones (las profesiones que luego se convertirían en los principales competidores de los abogados -los sociólogos y los economistas- solo adquirirán una presencia pública significativa durante la segunda mitad del siglo XX). Un mercado cerrado, con rentas protegidas, una posición social relativamente asegurada y una asociación gremial -el Colegio de Abogados- con potestades sancionadoras, deberían permitir la producción de profesionales que posean cercanía a la imagen funcionalista de los abogados.

Si estos factores ceden, sin embargo, la producción del tipo de profesionales recién descritos, debería disminuir, tornándose, por lo tanto, más frágiles los argumentos para promover el monopolio y el autocontrol de la profesión. ¿Cómo pueden ceder estos factores? Mi respuesta es que ceden cuando aumenta la competencia interna (al interior de la misma profesión) y externa (competencia por parte de otras profesiones) y los mecanismos de control interno pierden su efectividad. En el caso chileno las tres cosas han sucedido. Por una parte, de las cinco escuelas de derecho que existían en Chile hasta 1981, hemos pasado a alrededor de 41, con el consecuente aumento de abogados que ofertan sus servicios en el mercado. Respecto de la competencia externa, desde los setenta sociólogos, economistas y cientistas políticos han entrado decididamente a disputar la primacía de los abogados en la escena pública, llegando, a momentos, a relegarlos a posiciones subordinadas. Sobre esto, Mónica MADARIAGA, Ministra 
de Justicia del régimen militar, se refería al trato que los economistas prodigaban a los abogados señalando que "nos hacían sentir como insectos" 3 .

Así las cosas la situación actual de los abogados en Chile se asemejaría a aquella de los abogados en el mundo anglosajón después de lo que POLANYI ha denominado "la gran transformación": la penetración del mercado en todas las áreas de la vida ${ }^{4}$. Una vez que ceden las barreras de entrada a la profesión legal, se agotan -0 , al menos se tornan insignificantes-, los controles del ejercicio profesional por parte del Colegio de Abogados, y aumenta la competencia externa, los abogados y el mercado han quedado frente a frente. ¿Debiésemos entonces intentar conceptualizar a los abogados desde una perspectiva más cercana a la tradición weberiana? Desde mi punto de vista, la respuesta es que la tradición weberiana presta ayuda al momento de desplazar la imagen de los abogados desde sujetos altruistas a sujetos autointeresados, pero al menos en el caso chileno, falla en adjudicarles una identidad corporativa que, en Chile, solo se ha manifestado pálidamente. Según ha argumentado Austin SARAT, la adjudicación de identidad corporativa a un grupo cuantioso y disímil como el cubierto por la expresión abogados es simplemente un error. En palabras de este autor:

La profesión (legal) no debería ser entendida como la reunión de una serie de atributos esenciales ni como cohesionada en la forma de una herramienta utilizada para perjudicar el interés público. Los intereses de los abogados son demasiado vagos, complejos, y contradictorios para servir a cualquiera de esos dos propósitos 5 .

Probablemente haya sido la tradición marxista en sociología de las profesiones la primera en arrojar algo de luz sobre esto.

3 Ver Constable, Pamela y Valenzuela, Arturo: A Nation of Enemies: Chile under Pinochet. Norton, Nueva York, 1981, p. 171.

4 Magaly LARSON ha señalado que el origen de la fisonomía de las profesiones modernas se encontraría en la reorganización de la economía y la sociedad alrededor del mercado como una forma de conseguir una tajada del mismo garantizada por el Estado (ver The Rise of Professionalism. A sociological Analysis, University of California Press, Berkeley, 1977), lo que Weber denominó "la tendencia hacia la monopolización de oportunidades, frecuentemente económicas, específicas (ver Economy and Society, An Outline of Interpretative Sociology, Edited by Gunther Roth and Claus Wittich, Bedminster Press, New York, 1968, p. 342).

5 Ver The Profession Versus the Public Interest: Reflextions on Two Reifications, p. 1492 (en línea). En lawschool.stanford.edu/lawreview/content/vol54/6/Sarat.pdf - [consulta 7 de julio de 2003]. 


\section{LA TRADICIÓN MARXISTA}

El enfoque marxista sobre la sociología de las profesiones que ha llevado, por ejemplo Terence JOHNSON, examina el lugar de las profesiones desde las relaciones antagónicas entre trabajo y capital ${ }^{6}$. De este antagonismo se derivan dos cosas, la primera es que el poder de las profesiones resulta meramente contingente a los imperativos del capitalismo. La segunda -y más contingente a este trabajo- es la proletarización de las ocupaciones profesionales. La idea aquí es levemente distinta a la de MARX, no se trata de que el abogado únicamente tenga como capital a su prole, sino más bien al hecho que algunos segmentos de la profesión legal han perdido el poder de controlar su propio trabajo. En ciertos segmentos de la profesión legal, la autonomía que solía caracterizar el trabajo de los abogados ha dado paso a la burocratización del trabajo. Este es el caso de los abogados que trabajan como asociados en firmas de abogados, aquellos que trabajan en departamentos legales de empresas $y$, por supuesto, de aquellos abogados que desarrollan funciones asociadas al ejercicio de su profesión como funcionarios públicos.

\section{LA ESTRATIFICACIÓN}

El enfoque marxista parece estar en lo correcto cuando cuestiona la supuesta uniformidad de los profesión legal, los abogados. Conviene, sin embargo, detenerse con más cuidado en los patrones de estratificación que determinan los relieves y oquedades que desaconsejan referirse a los abogados como un todo cohesionado en torno a la consecución ciertos intereses comunes. Como ha sugerido ABEL, al interior de la profesión legal es posible distinguir numerosos patrones de estratificación como el nivel de riqueza, prestigio, el tipo de clientes para quien se trabaja, el área del derecho en el que el abogado se ha especializado, el trabajo independiente o al interior de una firma de abogados, el tamaño de la firma, la adscripción al sector público o privado, la educación legal que ha recibido etc.?

En el caso chileno es posible reconocer algunos de estos patrones. Así, por ejemplo, una profesión legal relativamente uniforme como la que existía en Chile hasta la primera mitad del siglo XX ha cedido el paso a una práctica crecientemente compleja y especializada ${ }^{8}$. Dentro de

6. Ver "Work and Power", en Esland, G. y SAlaman, G. (eds.): The politics of Work and Occupations, The Open University Press Milton Keynes, Londres, 1980.

Ver The Transformation of the American Legal Profession, en ABEL, Richard (ed.): Lawyers. A Critical Reader, The New York Press, Nueva York, 1997.

8 Ver VARGaS, Juan Enrique et al: "El rol del Estado y el mercado en la justicia", en Cuadernos de Análisis Jurídico $\mathrm{N}^{\circ} 42$, Escuela de Derecho, Universidad Diego Portales, Santiago, 2001, p. 140. 
ella es posible reconocer al menos dos patrones de estratificación? ${ }^{9}$. De ellos, probablemente el más visible sea la especialización. Una muestra elocuente de esto es el aumento por la demanda de abogados chilenos por programas de posgrado (diplomados, maestrías, doctorados) tanto en universidades chilenas como extranjeras y un explosivo aumento en la oferta de estos por parte de las primeras. En conjunto con lo anterior, otro patrón de estratificación es la presencia creciente de distintas formas de ejercicio de la profesión asociativas. Los más frecuentes son las comunidades de techo, las empresas de abogados, los departamentos legales y las clínicas legales ${ }^{10}$.

\section{UN ENFOQUE COMPLEMENTARIO}

$\mathrm{Al}$ interior de un mercado competitivo en el que los abogados deben proteger sus rentas tanto respecto de la competencia interna como externa, el autointerés que utiliza la tradición weberiana constituye un punto de partida valioso para examinar la profesión legal. De lo que resulta necesario desprenderse en cambio es del holismo de esta teoría. Cuando se utiliza la expresión abogados -aun prescindiendo de aquellos graduados en derecho que se dedican a la actividad judicial - se está aludiendo, en verdad, a un agregado social, cuyos integrantes poseen pocas cosas en común más allá de los estudios formales de derechos y un título de grado $^{11}$. El problema entonces es cómo hacerse cargo de las diferencias que es posible percibir entre los abogados.

Una posibilidad que resulta atractiva es intentar desagregar la categoría abogados en subcategorías que permitan identificar con mayor precisión las características que determinan la fisonomía de cada grupo.

9 Orros patrones de estratificación, que presentan grados significativos de superposición con estos son las escuelas de derecho de donde provienen los alumnos y su capital social. Sobre esto ver DE LA MAZA GAZMURi, IÑIGo: "Los abogados en Chile: desde el Estado al mercado", Informe de Investigación nímero 10, año 4, enero 2000, Centro de Investigaciones Jurídicas. Facultad de Derecho, Universidad Diego Portales.

11 Ya se ha advertido que ese conocimiento que se deriva de los estudios de derecho y que es certificado por el título de abogado es determinante -aunque por distintas razonestanto para el enfoque funcionalista como para la tradición weberiana. En el caso de los abogados, la forma en que se transmite ese conocimiento juega un papel determinante, justificando, en último término, el monopolio sobre la provisión de "mercancía legal" que el Estado reconoce a los abogados y su capacidad de autocontrol. A diferencia de otras profesiones - las científicas- que basan estas prebendas en proposiciones descriptivas, los abogados las derivan de proposiciones normativas o morales (ver HALLIDAY, Terence: Beyond Monopoly, Lawyers State Crises, and Professional Empowerment, The University of Chicago Press, Chicago, 1987, pp. 28-55). Si bien el conocimiento que obtienen de las escuelas de derecho los abogados constituye una característica común a la profesión y ayuda a explicar como consiguieron la protección estatal sobre el monopolio de sus funciones y un prestigio social -actualmente algo decadente-, resulta insuficiente para dar cuenta de las diferencias que es posible advertir al interior de la profesión. 
Siguiendo el enfoque de los "tipos profesionales" de BRANTE, es posible desplazar el eje del modelo desde la profesión -la abogacía- hacia los tipos de ocupaciones que existen al interior de una misma profesión. En el caso de la profesión legal, es posible identificar cuatro tipos principales: (1) los abogados que ejercen liberalmente, (2) aquellos que ejercen bajo esquemas asociativos que privilegian la burocratización, (3) los abogados que se dedican al mundo académico y (4) los abogados que sirven al Estado ${ }^{12}$.

Para BRANTE, este enfoque posee al menos tres ventajas. En primer lugar permite advertir que algunas diferencias que surgen al comparar diversas profesiones se encuentran cercanamente relacionadas con el tipo de ocupación dominante al interior de cada profesión. En segundo lugar permite explicar algunas tensiones que existen al interior de las propias profesiones, las que en definitiva se deberían a la persecución de intereses divergentes, e incluso contradictorios, por parte de quienes pertenecen a cada tipo profesional. Finalmente, este tipo de enfoque facilitaría la comparación entre profesiones de países diversos. En este sentido, parece más probable que un abogado de una prestigiosa empresa de abogados chilena registre mayores coincidencias en el ejercicio de su profesión con un abogado de una empresa de abogados estadounidense que con otro abogado chileno que trabaja exclusivamente para un servicio asistencial dependiente del Estado.

\section{Especulando acerca del CASO CHILENO}

A pesar de la escasa evidencia disponible, aplicando el enfoque recién descrito a los abogados en Chile hoy pueden decirse algunas cosas, quedando pendiente, sin embargo, su plausibilidad empírica.

\section{El ejercicio liberal y el ejercicio asociativo de la profesión ${ }^{13}$}

De una parte parece posible sostener que aun cuando en Chile el ejercicio liberal es el patrón dominante de ejercicio profesional, este carácter dominante se deriva de la cantidad y no en cambio del prestigio.

12 Ver "An actor-based framework for the study of the professions", en Burrage, Michael y Torstendal, Rolf (eds.): Professions in Theory and History. Retbinking the Study of the Professions, Sage Publications, Worcester, 1990, p. 208.

13 Utilizo la expresión ejercicio liberal en un sentido diverso al que comúnmente se le da, siguiendo a Falcao, sostendré que los rasgos que caracterizan el ejercicio liberal de la profesión legal son la autonomía, la libertad y la independencia respecto del cliente (ver FALCAO, Joaquín: "Lawyers in Brazil" en Abel, Richard y Lewis, Phillip (eds.): Lawyers in Society, Volume 1I: The Civil Law World, Universicy of California Press, Berkeley, 1998, p. 427). 
Aunque aún se registran excepciones notables, la tendencia parece ser a que los grandes clientes opten por transferir sus necesidades legales a abogados que participan de alguna forma de ejercicio asociativa. Así, el modelo del abogado de la primera mitad de siglo, un profesional que trabaja solo o únicamente acompañado de su secretaria parece encontrarse en franca retirada. El ejercicio asociativo no es, sin embargo, un continente cuya composición sea homogénea. En el caso chileno probablemente sea la comunidad de techo la forma más común de practicarlo. No obstante lo anterior, no es esta última la forma más prestigiosa de ejercicio asociativo. Actualmente dos formas de ejercicio asociativo parecen gozar de mayor prestigio: las empresas de abogados y las boutiques de abogados. Para estos efectos una empresa de abogados puede ser definida en la forma que lo hace el Black's Law Dictionary, como una asociación de abogados que ejerce conjuntamente y usualmente comparten clientes y ganancias, en una empresa tradicionalmente organizada como una sociedad de personas, pero también, frecuentemente, como una corporación profesional o una compañía de responsabilidad limitada. Lo que suele caracterizar a la empresa de abogados son las asimetrías que es posible detectar entre quienes trabajan en ella. Algunos de ellos -los socios-son, en verdad, los dueños de la empresa, los otros -los asociados- se asemejan a los empleados que trabajan bajo subordinación y dependencia de los primeros. Las boutiques de abogados se caracterizan en cambio por la simetría entre sus asociados, por lo general, abogados de prestigio y con experticia en temas determinados sobre los cuales ofrecen sus servicios.

Ahora bien, aunque numéricamente las empresas de abogados y las boutiques no son aún relevantes en Chile, poseen importancia simbólica para el resto de quienes ejercen bajo modalidades asociativas distintas. Dicho de otra manera, constituyen modelos aspiracionales que los demás abogados, con mayor o menor acierto, intentan emular. Estos dos son, pese a su insignificancia numérica, según me parece, los modelos de ejercicio más significativos en el ejercicio de la abogacía.

\section{Hacia una clase académica}

Hablar del tercer tipo ocupacional al interior de la profesión legal es todavía algo engañoso en Chile. La razón de lo anterior es que como se ha advertido, históricamente Chile ha carecido de ella. Durante la década de los noventa, sin embargo, esto parece estar cambiando. Existe un conjunto de Escuelas de Derecho -v. gr. la de la Universidad Diego Portales, de Talca, los Andes, Católica de Santiago y Adolfo Ibáñez-que han realizado significativos esfuerzos por engrosar sus plantas docentes con profesores con jornadas dedicadas a la investigación. La explicación de lo anterior posiblemente resida en dos factores. El primero de ellos es la redistribución de las rentas al interior de la abogacía, quedando seve- 
ramente desmejorados los profesionales más jóvenes y, disminuyendo, por lo tanto, el costo de oportunidad de dedicarse a la docencia. El segundo es el aumento en la competencia entre las escuelas de derecho por captar buenos alumnos, lo que ha determinado un aumento en la demanda por profesores jornada.

Como en el caso anterior, este es todavía un fenómeno incipiente, pero no obstante ello, relevante. La razón de lo anterior es que, por regla general, los académicos de jornada serán cualitativamente superiores a aquellos que únicamente dedican una fracción marginal de su tiempo a la enseñanza del derecho. Si esto es correcto, es posible considerar que, aún en desventaja numérica, serán los abogados que se dediquen con mayor intensidad a la academia quienes dictarán las pautas de la actividad académica. Lo anterior ha determinado -y debería continuar haciéndolo con mayor intensidad-severos cuestionamientos a la enseñanza del derecho que en algunos casos se han plasmado en reformas a los currículos y metodologías de enseñanza de las escuelas de derecho.

\section{Los abogados y el Estado}

En otra parte he sostenido que la evolución de los abogados en Chile puede resumirse como un tránsito desde el Estado hacia el mercado ${ }^{14}$. Esto no quiere decir que el sector público se haya despoblado de abogados, sino que la relevancia del discurso de los abogados en el sector público ha perdido la relevancia que tuvo en Chile hasta mediados del siglo XX, dejando lugar al discurso de otras profesiones como los economistas, sociólogos y cientistas políticos. En este sentido, mi impresión no es que la cantidad de abogados que opera al interior del sector público haya disminuido, es probable que haya sucedido todo lo contrario. No obstante lo anterior, parece más o menos claro que los abogados han dejado de ser la "profesión del poder"15 o, al menos, han comenzado a compartir ese poder con otras profesiones. Así las cosas, parece ser que la hegemonía de los abogados en el sector público se ha desgastado, reservándose, en la mayoría de los casos, a aquellos asuntos que genuinamente precisan de una cierta experticia legal.

\footnotetext{
14 Ver "Los abogados en Chile: desde el Estado al mercado" (n. 10)

is En este sentido Bernardino BRAVO, por ejemplo, ha señalado que durante gran parte del siglo XIX y las primeras décadas del siglo XX fue el hombre de Estado (ver Estudios de derecho y cultura de abogados en Chile 1758-1998: "Tras la huella del ius commune, la codificación y la descodificación en el Nuevo Mundo", Revista de Estudios Históricos-Juridicos, $\mathrm{N}^{\circ} \mathrm{XX}, 85,106 ; 1998,96$ ), En la misma línea, Sol SERrano ha afirmado que "es un lugar común señalar que leyes fue la profesión de la clase dominante" (Universidad y Nación: Chile en el Siglo XIX, Editorial Universitaria, Santiago, 1994, p. 177).
} 


\section{IN MEDIO VERITAS EST}

Resulta tentador encapsular a los abogados dentro de una sola imagen -casi tan tentador como encapsular geográficamente al bien y el mal-, pero a la vez es inútil -y en el caso del bien y el mal, simplemente necio-. Probablemente la única característica más o menos común que identifica a los abogados es un conjunto de conocimiento que les han sido transferidos, con mayor o menor fortuna, durante su paso por la universidad y un diploma que lo acredita. Las diferencias que existen entre quienes denominamos abogados, sin embargo, hacen que esta semejanza se torne baladí. Los abogados no son héroes ni rufianes, exitosos hombres de negocios o abnegados servidores del Estado o de los más pobres, tecnócratas especializados o generalistas ilustrados. La razón de esto es simplemente que la expresión abogados es demasiado amplia como para poder registrar esas regularidades al interior del grupo que designa.

Revisando la historia de los abogados -quienes poseen un título de tales- en Chile es posible, al menos utilizar los modelos holísticos para decir que no son los abogados. Por una parte es imposible definirlos como sujetos altruistas que persiguen el bien común. En un mercado extraordinariamente competitivo como el que actualmente existe, la idea de sujetos autointeresados parece una base más fructífera para comenzar a examinar la profesión. Para que el análisis sea realmente útil, sin embargo, es necesario introducir algunos elementos nuevos al modelo. He sugerido que un comienzo auspicioso es desagregar la categoría abogados según las ocupaciones que suelen desarrollar quienes poseen títulos de abogado. Esto, por supuesto, no termina de captar todas las sutilezas del desempeño profesional de los abogados, pero entrega algunas pistas sobre las tendencias que es posible advertir actualmente al interior de la profesión legal en Chile actualmente.

\section{BiBLIOGRAFÍA CONSULTADA}

- ABEL, Richard: "The Transformation of the American Legal Profession", en ABEL, Richard (ed.): Lawyers. A Critical Reader, The New York Press, Nueva York, 1997.

- BRANTE: "An actor-based framework for the study of the professions", en Burrage, Michael y Torstendal Rolf (eds.): Professions in Theory and History. Rethinking the Study of the Professions, Sage Publications, Worcester, 1990.

- Bravo LiRA, Bernardino: Estudios de derecho y cultura de abogados en Chile 1758-1998: "Tras la huella del ius commune, la codificación y la descodificación en el Nuevo Mundo", en Revista de Estudios Históricos-Jurídicos, $\mathrm{N}^{\circ} \mathrm{XX}, 1998$. 
- Constable, Pamela y Valenzuela, Arturo: A Nation of Enemies: Chile under Pinochet, Norton, Nueva York, 1981.

- De la Maza Gazmuri, Iñigo: "Los abogados en Chile: desde el Estado al mercado", Informe de Investigación número 10, año 4, enero 2000, Centro de Investigaciones Jurídicas. Facultad de Derecho, Universidad Diego Portales.

- FAlCAO, Joaquín: "Lawyers in Brazil", en ABEL, Richard y LEWIS, Phillip (eds.) Lawyers in Society, Volume II: The Civil Law World, University of California Press, Berkeley, 1998.

- Halliday, Terence: Beyond Monopoly, Lawyers State Crises, and Professional Empowerment, The University of Chicago Press, Chicago, 1987.

- Johnson, Terence: "Work and Power", en Esland, G. y Salaman, G. (eds): The politics of Work and Occupations, The Open University Press Milton Keynes, Londres, 1980.

- LARSON Magaly: The Rise of Professionalism. A sociological Analysis, University of California Press, Berkeley, 1977.

- Parsons, Talcott: Essays in Sociological Theory, revised edition, second printing, Illinois, 1958.

- Sarat, Austin: The Profession Versus the Public Interest: Reflextions on Two Reifications, p. 1492 (en línea). En lawschool.stanford.edu/lawreview/content/vol54/6/Sarat.pdf - [consulta 7 de julio de 2003].

- Serrano, Sol: Universidad y Nación: Chile en el Siglo XIX, Editorial Universitaria, Santiago, 1994.

- VARgAs, Juan Enrique et al.: "El rol del Estado y el mercado en la justicia", en Cuadernos de Análisis Jurídico $\mathrm{N}^{\circ} 42$, Escuela de Derecho, Universidad Diego Portales, Santiago, 2001.

- Weber, Max: Economy and Society, An Outline of Interpretative Sociology, Edited by Gunther Roth and Claus Wittich, Bedminster Press, New York, 1968.

- Weber, Max: American Lawyers, Oxford University Press, Nueva York, 1989. 